\title{
Degradation Control of Walls with Rising Damp Problems
}

\author{
A.S. Guimarães ${ }^{1, a}$, J.M.P.Q. Delgado ${ }^{1, b}$ and V.P. de Freitas ${ }^{1, c}$ \\ ${ }^{1}$ LFC - Laboratório de Física das Construções, Departamento de Engenharia Civil, Universidade \\ do Porto, Rua Dr. Roberto Frias, s/n; 4200-465 Porto, Portugal \\ aanasofia@fe.up.pt, bjdelgado@fe.up.pt, cvpfreita@fe.up.pt
}

\begin{abstract}
Keywords: Rising damp treatment; Historic buildings; Moisture transfer; Wall base ventilation system; Evaporation.
\end{abstract}

\begin{abstract}
Degradation in walls of Historical Building with rising damp is a complex problem to solve, due to the thickness and heterogeneity of those walls. The traditionally treatment techniques used (such as watertight barriers, injection of hydrofuge products, etc.) show, sometimes, to be ineffective or too expensive, justifying the need to find a new approach. Experimental studies validate the effectiveness of a new treatment technique applied to the walls of old buildings - wall base ventilation system.

Building Physics Laboratory (LFC) is developing a model of this technique. The sizing of the treatment system is based on knowledge of the characteristics of the wall, of the geometry of the ventilation system and of the building being dealt with.

In this work it is described the moisture transfer process between the moving air flux, inside the system, and the wall. Experimental results were used to validate the mathematical solution and the values obtained are very similar.
\end{abstract}

\section{Introduction}

Humidity is one of the main causes of decay in buildings, particularly rising damp, caused by the migration of moisture from the ground through the materials of the walls and floors via capillary action. This water comes from groundwater and surface water. The height that moisture will reach through capillary action depends upon factors such as the quantity of water in contact with the particular part of the building, surface evaporation conditions, wall thickness, building orientation and the presence of salts.

In historic buildings, rising damp is particularly difficult to treat, due to the thickness and heterogeneity of the walls. Traditional methods of dealing with this problem (chemical or physical barriers, electro-osmosis, etc) have proved somewhat ineffective. There is therefore a need to study new systems [1]. In recent years, experimental research into the effectiveness of wall base ventilation systems (natural or hygro-regulated) to reduce the level of rising damp, conducted at the Building Physics Laboratory has yielded interesting results. This is possible only when the groundwater is lower than the base of the wall [2]. Numerical simulation studies, using the programme WUFI-2D, have given similar findings.

This paper describes a new system for treating rising damp in historic buildings based upon a hygro-regulated wall base ventilation system, and analyses the results obtained following implementation of the system in laboratory tests.

\section{Rising Damp Treatment - Traditional Technologies}

In Portugal there are several historical buildings damaged by rising damp and by the presence of salts that crystallizes and dissolve. Walls with problems caused by rising damp can be treated by any of the following traditionally technologies: execution of a damp-proof course, creation of a potential against the capillary potential, installing atmospheric drainage / ventilation pipes, applying coating with controlled porosity and porometry and hiding the anomalies. 
Execution of a Damp-Proof Course: The main aim of this technique is to create a physical (walls partial replacement, Massari method or Schöner Turn method) or chemical barrier (by diffusion or injection) at the base of the affected walls to prevent capillary suction. This is achieved by reducing the absorbent section, introduction of water tight barriers or introduction of hydrofuge products.

Walls partial replacement - This procedure consists on the substitution of some elements of masonry material by waterproof bituminous type. Another way to perform the hydride hack consists of carrying out a RIP on the wall, that are filled with watertight materials including, bitumen, lead plates, sheets made of polyethylene or polyvinyl chloride and mortars of synthetic binders, having been taken to ensure the continuity of material. One thing to not neglect is a guarantee of fulfilment of free spaces after application of waterproof material which do not occur later settlements.

Massari method - The Massari method relies on implementing successive holes fuelling a first series of hurricanes tangent to each other and subsequently executed a second series with centres in previous points of tangency. After carrying out drilling is carried out the cleaning and filling it with mortar of synthetic binders. Waits himself harden mortar and proceed to the next section.

Schöner Turn method - This technique consists in the introduction of corrugated stainless steel plates on the walls to treat, using pneumatic hammers.

The chemical barriers should be located as close as possible to the ground level, about $15 \mathrm{~cm}$ above. For the introduction of products it is necessary to made holes along the wall, in about 10 to $20 \mathrm{~cm}$ and with a depth of approximately $1 / 3$ of the thickness of the wall. If pierce only on one side the depth must be $2 / 3$ of the thickness of the wall. After the completion of drilling begins and introduction of products through one of the following techniques:

Diffusion - This technique is based on gravity. The holes run either horizontal or inclined towards the base of the wall. In those holes will be introduced bottles containing the product selected.

Injection - In this case the product will be introduced on the wall with the help of some pressure equipment, which will be directly connected to the set of tubes placed in drilling carried out. The pressure used in this type of equipment may vary depending on the porosity and mechanical strength of the material, usually not exceeding $0.4 \mathrm{MPa}$. This pressure has the advantage of facilitating the expulsion of the water contained in the pores, thus facilitating the market penetration of the product and its homogeneous continuous distribution.

Creation of a Potential against the Capillary Potential: Creating an electric potential to drive the capillary flow downwards will lower the level reached by rising damp, but in practice the results of this technique have not been found to be very effective.

Electro-osmosis passive - It is necessary to link the electrodes of the wall (anode) with the ground (cathode). The electrodes are similar.

Electro-osmosis semi-passive - Technique similar to the previous one, whose difference is in the introduction of tension because the electrodes are constructed of other materials than creates a kind of electric stack.

Electro-active osmosis - In this technique it is standing between the electrodes of the wall and the ground a source of low-voltage DC power that helps to establish a potential difference, difference which should be limited to a maximum of 1.6 Volt lest they give the electrolysis of water.

Electro-osmosis phorese - This technique aims to fill one of the main drawbacks of the previous proceedings, which is the interruption of the system. In this case the anode is copper and the cathode galvanized steel, and it is introduced "phoresis" products containing metal particles in suspension. Running the system under the current action created by the "stack", the water moves by dragging with the products that will fill the capillary tubes. So, after a year and a half or two years, the tubes are totally filled and the system can be stopped.

Atmospheric Drainage / Ventilation Pipes: The underlying principle of atmospheric drains or Knappen siphons is based on the fact that damp air is heavier than dry air. Knappen believed that inserting oblique drainage tubes in the walls would immediately release damp air (coming from inside the wall), making the wall-drying process easier. 
Coatings with Controlled Porosity and Porometry: Applying outer coatings, by conducting wallboard with sub-layers with distinct characteristics to the decreasing of porosity go outside to the inside, that do not prevent the evaporation of humidity from inside the walls and stop the salt crystallization from leading to deterioration is a technique that hides the problem.

Hiding the Anomalies: The aim of this technique is not eliminating the underlying causes of the rising damp. A new wall may be erected, with a ventilated air chamber separating it from the original wall. This is a type of damp-proof course and ensures flaw concealment. The action code consists in implementing an interior wall, small wall thickness, separated by about $10 \mathrm{~cm}$ without any point of contact with this, to create an air space between the wall and the sieve being ventilated to the outside space allowing an effective evaporation. Ventilation is achieved through holes located at different levels. The base of the wall must be impermeable to guarantee non continuity. It is not acceptable conduct ventilation of air space for the interior of the building.

Comparative Analysis of the Different Treatment Techniques: All the aforementioned techniques for treating rising damp have advantages and disadvantages. Creating a damp-proof course system by reducing the absorbent area is an interesting idea but not often used for aesthetic and structural reasons. Creating watertight barriers causes vibration that can bring about stability problems. Introducing hydrofuge products has little effect when dealing with very thick and very heterogeneous walls, as is usually the case in historical buildings. Creating electric potential and installing Knappen siphons are techniques that are considered ineffective.

The main drawback of applying coatings with controlled porosity and porometry is that this technique cannot be used on walls without renderings (and most of our historical buildings don't have rendering). Hiding anomalies behind a wall built with a ventilation space separating it from the original wall would undoubtedly be effective if correctly done. Nevertheless, in addition to reducing space, concealing original walls may not be viable for historical buildings.

The conclusion is that none of the techniques described is particularly adequate for treating rising damp in historical buildings (see Table 1). Traditionally used techniques are in most cases not effective or too expensive due to the thickness and heterogeneity of the walls.

In recent years, experimental research into the effectiveness of wall base ventilation systems (natural or hygro-regulated) to reduce the level of rising damp, conducted at LFC, has yielded interesting results. Numerical simulation studies, using the programme WUFI-2D, have given similar findings [3]. The wall base ventilation is a creation of ventilated peripheral channels that reduces water contact with porous walls and enhances the evaporation conditions of the absorbed water. This evaporation takes place below floor level. The installation of a hygro-regulated mechanical ventilation device can increase the effectiveness of this system.

Table 1 - Comparative analysis of the different traditional treatment techniques.

\begin{tabular}{|l|c|c|c|c|}
\hline \multicolumn{2}{|c|}{ Method } & Effectiveness & Appearance & Limitations \\
\hline \multirow{2}{*}{$\begin{array}{c}\text { Execution of a damp- } \\
\text { proof course }\end{array}$} & $\begin{array}{c}\text { Reducing absorbent } \\
\text { section }\end{array}$ & Bad, Mean & Bad & $\begin{array}{c}\text { Not used for aesthetic and } \\
\text { structural reasons }\end{array}$ \\
\cline { 2 - 5 } & Water tight barriers & Good & Mean & $\begin{array}{c}\text { Causes vibrations that can lead to } \\
\text { stability problems }\end{array}$ \\
\cline { 2 - 5 } & Hydrofuge products & Very Good & Good & $\begin{array}{c}\text { Has little effect on very thick and } \\
\text { very heterogeneous walls }\end{array}$ \\
\hline $\begin{array}{l}\text { Creation of a potential against the } \\
\text { capillary potential }\end{array}$ & Bad & Good & Considered ineffective \\
\hline $\begin{array}{l}\text { Installing atmospheric } \\
\text { drainage/ventilation pipes }\end{array}$ & Bad & Mean & Considered ineffective \\
\hline $\begin{array}{l}\text { Applying coating with controlled porosity } \\
\text { and porometry }\end{array}$ & Mean, Good & Good & Cannot be used on non- \\
\hline plastered walls
\end{tabular}




\section{Wall Base Ventilation System}

The technique, called "HUMIVENT", consists of ventilating the base of walls through the installation of a hygro-regulable mechanical ventilation device. Wall base ventilation increases evaporation, which leads to a reduction in the level achieved by the damp front. This is possible only when the groundwater is lower than the base of the wall [3].

It was also possible to develop a new device that controls the ventilator considers some studied parameters. The hygro-regulable engine is now working properly. This device is absolutely new and it was the result of some years of work on this area. This system was validated in laboratory and using a 2D program to simulate its behaviour, WUFI-2D. The geometry was characterized experimentally and simultaneously it was monitories a Church in North of Portugal, since 2004. This information was essential to conclude about the best criterions of hygro-regulable mechanical ventilation device.

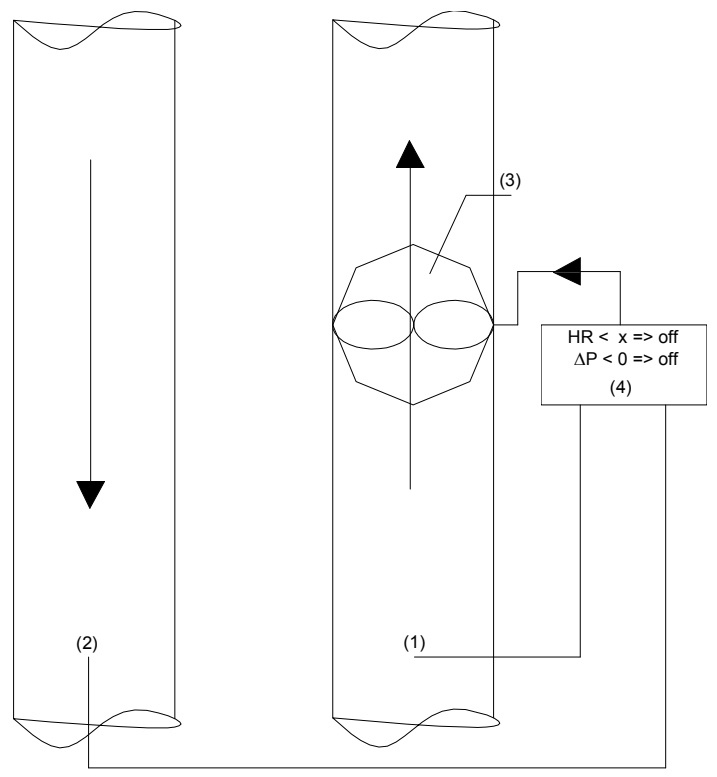

Legend: Probe (1) - Entrance (temperature and relative humidity); Probe (2) - Exit (temperature and relative humidity); Variable speed fan (3).

Control module (4): Probe $1-\theta_{1}$ and $\mathrm{RH}_{1}=>$ vapour pressure $1(\mathrm{~Pa})$; Probe $2-\theta_{2}$ and $\mathrm{RH}_{2}$ $\Rightarrow$ vapour pressure $2(\mathrm{~Pa})$. Calculation of $\Delta P$ $=\mathrm{P}_{2}-\mathrm{P}_{1}$. Fan operation instruction: On if $\Delta P \geq$ 0 and $\mathrm{HR}_{1}>$ predetermined value. Off if $\Delta P$ $\leq 0$ or $\mathrm{HR}_{1}<$ predetermined value.

Figure 1 - Operate principle of the hygro-regulated wall base ventilation system.

The extraction is know controlled by a variable speed motor, hygro-regulated which comes into operation when the water vapour pressure at the entrance is lower than the vapour pressure at the exit, resulted from the combination of the temperature and the relative humidity, and when the relative humidity of the air entry is higher than a certain predefined value to guarantee it will not have problems of salt crystallization/dissolution inside the system (see Figure 1). The control module receives information from two probes (temperature and relative humidity at the entrance and at the exit), calculates the vapour pressure of water at the entrance and at the exit, evaluates the positive or negative sign of the pressure differential, shutting on or down the fan.

\section{Analytical Analysis of the Evaporative Process}

The "HUMIVENT" technique consists of ventilating the base of walls using a natural ventilation process or by installing a hygro-regulated mechanical ventilation device. In terms of analytical analysis, we considered that the wall base ventilation system is a flat plane along which air is flowing close to the "saturated" wall $(0<z<L)$. The analytical solution proposed by Crank [4] to describe diffusion process in a semi-infinite flat surface is

$$
\frac{c-c_{0}}{c^{*}-c_{0}}=\operatorname{erfc}\left(\frac{y}{2 \sqrt{D_{\mathrm{m}} z / u}}\right)
$$

where $c_{0}$ is the bulk concentration of water vapour, $c^{*}$ is the equilibrium concentration of water vapour, $D_{\mathrm{m}}$ is the molecular diffusion coefficient and $u$ is the air velocity. The total rate of evaporation, $n$, may be calculated over the whole wall surface 


$$
n=\int_{0}^{L} N h_{\mathrm{H}} d x=\left(c^{*}-c_{0}\right) h_{\mathrm{H}} L\left(\frac{4 D_{\mathrm{m}}}{\pi L / u}\right)^{1 / 2}
$$

where the flux of evaporation is given by $N=-D_{\mathrm{m}}(\partial c / \partial y)_{y=0}$ and $h_{H}$ is the width of HUMIVENT system. The evaporation potential for the HUMIVENT system, $e_{H}$, given by

$$
e_{H}=\frac{n}{L . h_{H} \rho_{w}}=\frac{\left(c^{*}-c_{0}\right)}{\rho_{w}}\left(\frac{4 D_{\mathrm{m}}}{\pi L / u}\right)^{1 / 2}
$$

where $\rho_{\mathrm{w}}$ is the water density.

\section{Rising Damp Theory}

The rising damp phenomenon can be analysed using the sharp front model developed by Hall and Hoff [5]. This model describes the relationship between sorptivity, $S$, wall thickness, $b$, evaporation potential, $e$, liquid bulk volume, $\theta_{\mathrm{w}}$ and capillary rise heights, $h$.

Considering the absorption inflow and evaporation loss to be balanced and considering a rising damp steady state, the following analytical solution for the equilibrium height, $h_{\infty}$, is obtained [5],

$$
\frac{b S^{2}}{2 \theta_{\mathrm{w}} h_{\infty}}=e h_{\infty} \quad \text { or } \quad h_{\infty}=S \sqrt{\frac{b}{2 e \theta_{\mathrm{w}}}}
$$

If we consider a rising damp steady state, involving a wall base ventilation system (HUMIVENT) located on both sides above the base (see Figure 2 - Conf. 2), Eq. (4) produces

$$
\frac{b S^{2}}{2 \theta_{\mathrm{w}} h_{\infty}}=e\left(h_{\infty}-h_{H}\right)+e_{H} h_{H}
$$

and the steady-state height of rise given by

$$
h_{\infty}=\left(1-\frac{e_{H}}{e}\right) \frac{h_{H}}{2}+\sqrt{\frac{b S^{2}}{2 \theta_{\mathrm{w}} e}+\left(\frac{e_{H}}{e}-1\right)^{2} \frac{h_{H}^{2}}{4}}
$$

\section{Experimental Set-Up}

The laboratory study carried out in the Building Physics Laboratory (LFC) at FEUP aimed to characterise how walls are affected by the phenomena of rising damp under different boundary conditions [3].

The physical model selected consisted of a prismatic wall $1.58 \mathrm{~m}$ high, $2.00 \mathrm{~m}$ long and $0.20 \mathrm{~m}$ thick, waterproofed on the two upper sides to prevent moisture entering from this direction. The limestone walls (with sorptivity coefficient, $S=2.40 \times 10^{-5} \mathrm{~m} / \mathrm{s}^{1 / 2}$ and liquid bulk volume, $\theta_{\mathrm{w}}=0.177$ ) were placed in a reservoir approximately $2.20 \times 2.50 \times 0.50 \mathrm{~m}^{3}$ made from cement blocks. To assess moisture transfer inside the walls, probes were inserted at different heights and depths to measure relative humidity and temperature. These probes were then connected to a data acquisition and recording system.

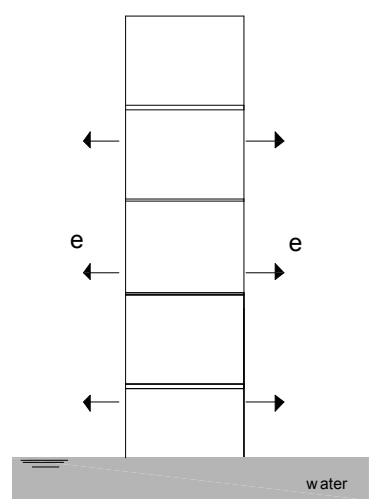

Configuration 1

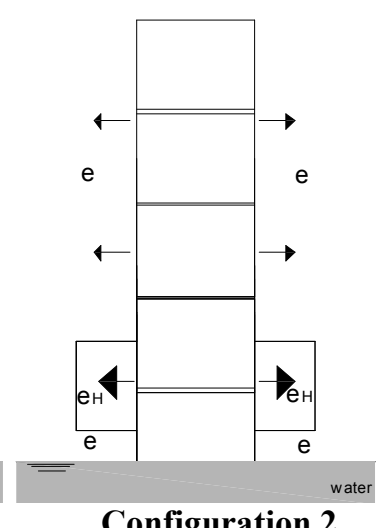

Configuration 2

Figure 2-Diagram of the different boundary conditions studied.

The configurations tested are shown in Figure 2. In Configuration 1 the base of the wall is immersed up to a height of $8 \mathrm{~cm}$ and, as we wished to assess the effect of the wall base ventilation system - HUMIVENT, in Configuration 2, a ventilation box was placed on both sides of the wall. To avoid turbulence, an air velocity of $0.083 \mathrm{~m} / \mathrm{s}$ was used. 


\section{Results and Discussion}

The climatic conditions inside the laboratory during the experiments were considered constant at a temperature of $23^{\circ} \mathrm{C}$ and a relative humidity of $58 \%$. Under these conditions and considering an air velocity inside the laboratory of $1 \mathrm{~cm} / \mathrm{s}$, the evaporation potential was given by [2]

$$
e=D_{m} \frac{\left(c^{*}-c_{0}\right)}{\rho_{w}} 0.646 \frac{\operatorname{Re}^{1 / 2} \mathrm{Sc}^{1 / 3}}{L}
$$

where Re is the Reynolds number and Sc the Schmidt number.

The resulting evaporation potential value is $0.46 \times 10^{-4} \mathrm{~mm} / \mathrm{min}$. The evaporation potential associated with the HUMIVENT system, $e_{H}$, is given in Eq. (7) as $2.17 \times 10^{-4} \mathrm{~mm} / \mathrm{min}$. If these values are inserted into Eq. (10), a steady state height of rise of $379.5 \mathrm{~mm}$ is obtained for Conf. 2 and a steady flow rate through the wall of about $27.1 \mathrm{~L} /$ year per metre length of wall. This value is very similar to the experimental results obtained, between $380 \mathrm{~mm}$ and $455 \mathrm{~mm}$, and significantly different from the steady state height of rise obtained without the use of the HUMIVENT system, Conf. 1, which was $h_{\infty}=510 \mathrm{~mm}$ (experimental value in the range $455-540 \mathrm{~mm}$ ).

The results of the experiment show that the presence of a wall base ventilation system on both sides prevents the damp front $\left(h_{\infty}=455-540 \mathrm{~mm}\right.$, in Conf. 1 vs. $h_{\infty}=380-455 \mathrm{~mm}$, in Conf. 2) and that the simple analytical model proposed by Hall and Hoff [6] clearly describes the rising damp front when compared with the experiment results. During the four months of experimental research, in laboratory tests on Configuration 2 the new treatment technique extracted approximately $11.8 \mathrm{~kg}$ of water (see Figure 3).

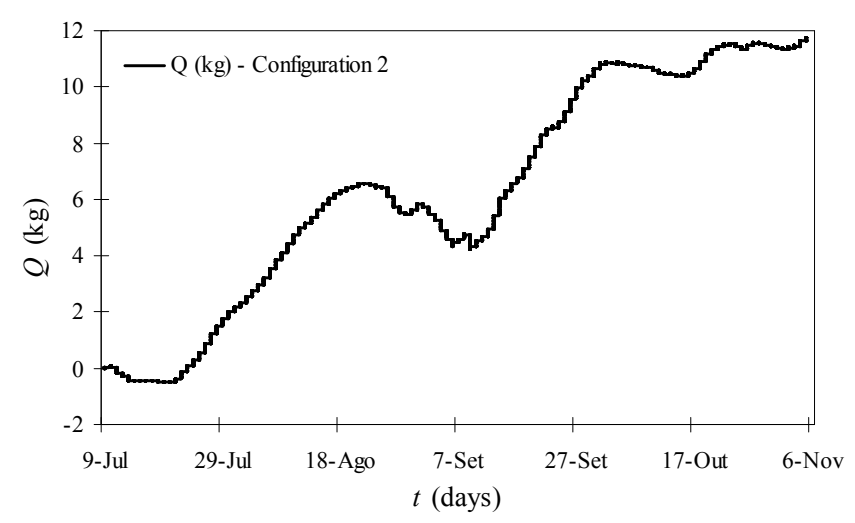

Figure 3 - Quantity of water vapour extracted in Configuration 2.

\section{Conclusions}

The mechanisms of moisture transfer are complex, particularly in terms of rising damp in historic buildings. As rising damp is one of the main causes of decay in these buildings, it is important to study the factors related to this phenomena.

Wall base ventilation is a simple technique that has a great practical potential and the experimental results performed at LFC-FEUP have shown that the placement of a wall base ventilation system on both side of the wall reduces the rising damp level.

The problem of moisture transfer between a saturated wall surface and the air flowing along it, lends itself to a simple full theoretical analysis, under an appropriate set of conditions.

The analytical model of rising damp predicts steady height of rise figures that are consistent with laboratory observations, which provide a good validation of the analysis. Using this model it is possible to scale the HUMIVENT system, optimise it and predict its behaviour.

\section{References}

[1] A.S. Guimarães, J.M.P.Q. Delgado and V.P. de Freitas: Dry Tech. Vol. 30 (2012), p. 1

[2] R. Colombert: L'Humidité des bâtiments anciens; causes et effets; diagnostic et remèdes (Editions du Moniteur, Paris, 1975).

[3] M.I.M. Torres and V.P. de Freitas: Build. Environm. Vol. 42 (2007), p. 424

[4] J. Crank: The mathematics of diffusion (Second ed., Oxford University Press, UK, 1975).

[5] C. Hall, W.D. Hoff and M.R. Nixon: Build. Environm. Vol. 19 (1984), p. 13 